\section{MULTIDOMAIN DETERRENCE AND STRATEGIC STABILITY IN CHINA}

\author{
LORA SAALMAN
}

\section{Introduction}

While politically China and the United States are farther apart than ever, there are indications that China's strategies in space, cyberspace and nuclear domains are increasingly converging with those of the USA, as well as Russia. This has implications for multidomain deterrence and strategic stability and could potentially facilitate future talks among these powers.

Over the past few years, China has displayed a wide range of military capabilities and infrastructure, including anti-satellite (ASAT) weaponry, multiple independently targetable re-entry vehicles (MIRVs), unmanned aerial and underwater vehicles (UAVs and UUVs), expanded intercontinental ballistic missile (ICBM) silos, and most recently a test of a hypersonic glide vehicle (HGV) coupled with a fractional orbital bombardment system (FOBS). ${ }^{1}$

An important question stemming from these military advances, and their visibility, is whether China's becoming more similar to-and in some cases surpassing-the USA and Russia in military capabilities is a stabilizing or destabilizing phenomenon. ${ }^{2}$

To answer the question, this SIPRI Insights on Peace and Security paper explores the current state of Chinese discussions on multidomain deterrence and strategic stability by examining two key concepts: active defence and proactive defence. It then assesses how these are being manifested in China through postural and technological indicators and what these trends may signify for USA-China strategic stability dialogues and potentially even future talks that include Russia.

\section{Multidomain strategic stability}

While the term 'strategic stability' is used frequently, it is interpreted differently in China, Russia and the USA. Chinese and Russian experts often argue

\footnotetext{
${ }^{1}$ The Soviet Union pursued a fractional orbital bombardment system during the cold war. For more information see e.g. Gyürösi, M., 'The Soviet fractional orbital bombardment system program', Technical Report APA-TR-2010-0101, Air Power Australia, updated Apr. 2012; Chen, S., 'Chinese scientists build anti-satellite weapon that can cause explosion inside exhaust', South China Morning Post, 21 Oct. 2021; and Sevastopulo, D. and Hille, K., 'China tests new space capability with hypersonic missile', Financial Times, 16 Oct. 2021.

${ }^{2}$ China is not typically characterized as a transparent power. Yet many of its recent military tests, deployments and infrastructure developments have been visible to satellite and other intelligence sources, offering de facto transparency, whether or not they are explicitly acknowledged by China.
}

\section{SUMMARY}

- Over the past few years, China has displayed a wide range of advances in military capabilities and infrastructure, including its test of a hypersonic glide vehicle coupled with a fractional orbital bombardment system and evidence of new intercontinental ballistic missile silos. While China and the United States remain at political odds, there are indications that China's strategies in space, cyberspace and nuclear domains are increasingly converging with those of the USA, as well as Russia. A key question is whether this strategic convergence is a stabilizing or destabilizing phenomenon.

To answer the question, this paper explores the current state of Chinese discussions on multidomain deterrence and strategic stability, with a focus on active defence and proactive defence. It then examines how these concepts are manifesting themselves in China's postural and technological indicators, including pre-mating of nuclear warheads to delivery platforms, expanded nuclear arsenal size, possible shifts towards launch on warning, integration of dualcapable systems, and advances in machine learning and autonomy. It concludes with a discussion of what these trends mean for future strategic stability talks. 
that applications of the term are vague and abstract, and in some cases even obstruct arms control progress. ${ }^{3}$ By contrast, US and European experts tend to apply the concept primarily in binary nuclear contingencies, emphasizing either the 'absence of incentives to use nuclear weapons first' (crisis stability) or the 'absence of incentives to build up a nuclear force' (arms race stability). ${ }^{4}$

As the factors influencing strategic stability expand beyond the nuclear arena to include space, cyberspace and other domains, the concepts and practices that underpin it merit re-examination. This has already begun in some cases, as with research at the Lawrence Livermore National Laboratory in the USA on the implications of multidomain complexity and emerging and disruptive technologies on strategic stability. ${ }^{5}$ Yet while this research indicates that the traditional notion of strategic stability is shifting, it has yet to redefine the term in the light of a multidomain environment.

In their current forms, 'crisis stability' and 'arms race stability' do not necessarily take into account ever-shifting technological advances and asymmetries found in non-nuclear domains. For example, military achieve-

While research indicates that the traditional notion of strategic stability is shifting, it has yet to redefine the term for a multidomain environment ments in autonomy and hypersonic glide suggest that China and Russia, which have historically maintained weaker conventional-and in China's case nuclear-forces compared with those of the USA, have begun to recalibrate their deterrence relations. As strategic stability crosses domains and is shaped by multidomain complexity, both official and independent experts have begun to use 'strategic stability' to replace the more concrete term 'arms control'. This is an important conceptual distinction, in that it impacts the outcomes of talks between countries in both positive and negative ways.

On the one hand, a broader range of countries may have a greater willingness to engage in strategic stability dialogues since such talks tend to focus more on how weapon systems are employed, whereas arms control negotiations concentrate on controlling their development. This expanded window for engagement could facilitate better mutual understanding of the multidomain conditions under which space, cyber or nuclear weapon systems might be used in a crisis or conflict. On the other hand, the reduced expectation of concrete deliverables in strategic stability dialogues means

\footnotetext{
${ }^{3}$ With regard to China, this is based e.g. on numerous panel discussions in which the author has participated, such as 'Strategic Stability: Impasse and Way Out' at the Beijing Xiangshan Forum, 25-26 Oct. 2021 and multiple iterations of the USA-China strategic dialogues held by the Pacific Forum, Naval Postgraduate School, China Arms Control and Disarmament Association and China Foundation for International and Strategic Studies. See also Carnegie Endowment for International Peace, 'Missile Defense and US-China Strategic Stability', Beijing, 10 July 2019. For discussion of the Russian perspective see e.g. Podvig, P., 'The myth of strategic stability', Bulletin of the Atomic Scientists, 31 Oct. 2012.

${ }^{4}$ See e.g. Acton, J. M., 'Reclaiming strategic stability', Carnegie Endowment for International Peace, 5 Feb. 2013.

${ }^{5}$ A 2021 report identifies areas of potential impact of multidomain complexity on different aspects of strategic stability, including the initiation of war, the perceived value and necessity of preemption, the control of war, the incentives for nuclear employment, the restoration of deterrence, and de-escalation and war termination. Roberts, B., Emerging and Disruptive Technologies, Multidomain Complexity, and Strategic Stability: A Review and Assessment of the Literature (Lawrence Livermore National Laboratory, Center for Global Security Research:Livermore, CA, Feb. 2021). See also Durkalec, J., Gasser, P. and Shykov, O., 5th Annual LLNL Deterrence Workshop: Multi-domain Strategic Competition: Rewards and Risks (Lawrence Livermore National Laboratory, Center for Global Security Research: Livermore, CA, Jan. 2019).
} 
that countries are less likely to agree to more binding constraints that could mitigate or forestall crises or arms races.

This was evident in recent talks between Russia and the USA, which are no longer labelled as arms control negotiations, but rather as strategic stability dialogues. ${ }^{6}$ By not pre-committing the two countries to negotiate restrictions-and instead paving the way to further talks-these dialogues leave the two countries free to engage in a more open-ended discussion that does not necessarily result in limits on their technological advances. For China, which has been reluctant to engage in arms control talks with the USA-much less trilaterally with Russia-due to concerns over the asymmetry

Two concepts are central to Chinese discussions on deterrence: 'active defence' and 'proactive defence' of the countries' military capabilities and the potential imposition of limits, strategic stability talks have greater appeal. While they may not restrict the further development of capabilities, such meetings offer an opportunity to address misperceptions and miscalculations contributing to escalation, thereby facilitating crisis management.

\section{Active defence and proactive defence}

In terms of strategic stability dialogues, there are grounds to believe that China may eventually consider involvement, despite its previous reticence. This is for several reasons. First, as noted above, the less-defined nature of strategic stability dialogues would allow China to discuss weapons employment and crisis management without necessarily limiting capabilities that could constrain its nuclear survivability. Second, China's evolving postures and growing capabilities in space, cyberspace, nuclear and other domains have begun to undermine its long-standing argument that its asymmetric weakness with regard to Russia and the USA precludes engagement in such talks.

To understand this logic, it is important to examine the underpinnings of China's stance on deterrence. Two concepts are central to Chinese discussions in this area: 'active defence' (积极防御) and 'proactive defence' (主动防御). Both of these concepts are evolving with the modernization of China's conventional and nuclear capabilities in response to its increasingly dynamic security environment. While historically 'active defence' has dominated nuclear discussions, the appearance of 'proactive defence' in space, cyberspace and even nuclear analyses and practice suggests that it will also be a factor in China's future strategies.

'Active defence' is reactive in nature, and implies readiness to use offensive action at the operational and tactical levels to retaliate against a provocation or attack. This concept appears predominantly in the nuclear domain and is frequently combined with such postures as no first use (NFU)-under which a country would not be the first to use nuclear weapons and would only use them in a second strike. ${ }^{7}$

\footnotetext{
${ }^{6}$ US Department of State, Office of the Spokesperson, 'Joint statement on the outcomes of the US-Russia Strategic Stability Dialogue in Geneva on September 30', Press release, 30 Sep. 2021; and White House, 'US-Russia presidential joint statement on strategic stability', 16 June 2021.

${ }^{7}$ While official statements are categorical that China maintains an NFU posture, there have been suggestions in informal debates that it should consider re-evaluating this posture, or even abandoning it. Most recently, this occurred in a speech at the China Arms Control and Disarmament
} 


\section{Proactive defence involves being prepared to use offensive measures on early warning of an impending attack, and even to pre-empt an attack}

Research conducted by the author uncovered over 18000 references in Chinese academic databases to 'active defence' (积极防御) in military, academic technical periodicals that include but are not limited to the People's Liberation Army Daily (解放军报), Military History Studies (军事 历史研究), Decision Making and Information (决策与信息) and Global Times (环球时报). The dominance of the term in periodicals that discuss domestic posture and target a general readership, combined with its usage in official documents issued by the Chinese Government, reflects its pervasive impact on strategists and their application of deterrence in China, particularly in the nuclear domain. ${ }^{8}$

As the name suggests, 'proactive defence' is proactive in nature. It involves being prepared to use offensive measures on early warning of an impending attack, and even to pre-empt an attack. In Chinese writings, it frequently appears in reference to the space and cyberspace domains, in the form of interdiction, disruption and asymmetric defence that overwhelms an opponent and increases the costs of the attack.

Research undertaken by the author found 2237 references in Chinese databases to 'proactive defence' (主动防御) in such journals as Military News (兵器知识), Winged Missile (飞航导弹), Modern Military (现代军事) Technical Forum (网界论坛), Home of Science and Technology Workers (科技工作者之家) and Aerospace Control (航天控制). Many of the periodicals in which it appears are aimed at a more specialist readership compared with those featuring active defence, yet they are also focused on domestic applications of the concept. This suggests that while proactive defence has not fully entered China's deterrence lexicon, it plays an important role among practitioners, including in such technical bodies as the Chinese Academy of Sciences, the China Classified Association's Science and Technology Branch, and the School of Information Science and Engineering at Central South University in Hunan. ${ }^{9}$

\section{Proactive defence in China's multidomain deterrence}

As China's space, cyberspace and nuclear operations increasingly focus on greater jointness in operations, crossover also occurs among these

\footnotetext{
Association by China's former arms control ambassador to the United Nations, who argued in his private capacity that China should reconsider its NFU pledge with regard to the USA. 沙祖康 大使在军控协会成立 20 周年纪念大会暨军控工作座谈会上的发言' [Ambassador Sha Zukang's speech at the 20th Anniversary Meeting of the Arms Control Association and the Arms Control Working Symposium], Juzizhoutou.net, 22 Sep. 2021.

${ }^{8}$ Chinese State Council Information Office, 新时代的中国国防 [China's national defence in a new era], 24 July 2019.

${ }^{9}$ Institute of Information Engineering, “网络空间内置式主动防御学术研讨会暨技术创新联盟・备 会议召 - ' [Academic seminar and preparatory meeting of the Technology Innovation Alliance on Proactive Defence in Cyberspace], Chinese Academy of Sciences, 13 July 2021; China Classified Association Science and Technology Branch, “国内网络主动防御技术现状探讨” [A discussion of the condition of domestic cyber proactive defence technology], DevSecOps [安全内参], 28 Nov. 2019; Huang, J. and Zhang, Z., “主动防御系统及应用研究' [Aggressive network defence and its application research], Network Security Technology and Application, vol. 21, no. 3 (2007); and Guangming Daily, ‘我国专家成功・发世界首套主动防御软件' [Our country's experts succeed in developing the world's first proactive defence software], Central People's Government of the People's Republic of China, 25 Sep. 2008.
} 
various domains. ${ }^{10}$ Thus, while 'proactive defence' has not replaced 'active defence' in Chinese concepts of deterrence, the impact of proactive defence on multidomain deterrence is only likely to grow as China moves towards greater jointness in its own operations-similar to those of the USA. Proactive defence has already begun to appear in Chinese writings-in reference not only to the USA, but also to China itself-as well as in Chinese practice.

On space, Chinese discussions of proactive defence include references to and concerns over the 2021 update of the 2018 US Air Force Doctrine Publication 3-14, Counterspace Operations and its details on ASAT systems and of electromagnetic and cyberspace operations against space assets. ${ }^{11}$ China's own development and testing of ASAT weapons, including recent reports about weapons designed to explode in the exhaust systems of satellites, indicate that it is charting a similar trajectory. ${ }^{12}$ Moreover, earlier off-therecord track-1.5 USA-China strategic dialogues revealed that

The impact of proactive defence on multidomain deterrence is only likely to grow as China moves towards greater jointness in its own operations China may consider an attack on US space assets during a conflict. Given the entangled or co-mingled nature of these systems, such a pre-emptive approach would have the potential for escalation from a conventional to a nuclear crisis.

On cyberspace, Chinese experts show the clearest shift towards proactive defence in both their writings and their application of the term. Chinese writings portray US documents such as the 2018 National Cyber Strategy of the United States of America as moving towards a stance based on proactive defence. Yet they are also explicit about China's own efforts to engage in pre-emption to thwart cyberattacks on its own critical infrastructure. ${ }^{13}$ This technological discussion covers both making China's systems more resilient against attack and engaging in offensive operations to intercept and destroy malware.

On nuclear, Chinese writings highlight the US discussion in the 2017 Joint Publication 3-01, Countering Air and Missile Threats on undertaking direct actions to destroy, eliminate or reduce the effectiveness of threats. ${ }^{14}$ This points to Chinese concerns over the US pursuit of missile defences and their ability to weaken China's nuclear deterrent. China's attempts to develop means of defeating US missile defences-for example through its testing of an HGV coupled with a FOBS, deployment of MIRVs on the DF-41 ICBM, and construction of new ICBM silos-also mark a more proactive approach.

Given the Chinese discussions of proactive defence in space, cyberspace and nuclear operations, it is not surprising that some Chinese strategists have

\footnotetext{
${ }^{10}$ World Outlook, “美国智库分析解放军 “主动防御” 战略(图)' [US think tank analyses the PLA's 'proactive defence' strategy (photo)], Sina.com.cn, 24 Dec. 2007; and China Classified Association Science and Technology Branch (note 9).

${ }^{11}$ US Air Force, Air Force Doctrine Publication 3-14, Counterspace Operations (Curtis E. Lemay Center, Air University: Maxwell Air Force Base, AL, 27 Aug. 2018), updated 25 Jan. 2021; and Zhang, H., “美国反太空作战能力详解!' [Detailed explanation of US anti-space combat capabilities!], China Command and Control Association, accessed 4 Nov. 2021.

${ }^{12}$ Chen (note 1).

${ }^{13}$ White House, National Cyber Strategy of the United States of America (White House: Washington, DC, Sep. 2018); and “网络安全新视野”美国网络攻击与主动防御能力体系发展综述 [A summary of the development of US cyberattack and proactive defence capabilities]', 网络安全新视野 [Advances in Cyber Security], 20 Dec. 2018.

${ }^{14} \mathrm{Yu}, \mathrm{L}$., “走出隐藏边界, 实施主动防御” [Stepping out of hidden boundaries, implementing proactive defence]', SEC-UN 安全村 [Security Village], 26 Mar. 2018.
} 
begun to conflate the two concepts of proactive defence and active defence. ${ }^{15}$ This has occurred primarily among Chinese cyberspace experts but has corollaries in other domains. For example, in the aerospace domain, China's flight of an estimated 150 military aircraft-including 12 nuclear-capable H-6 bombers-into Taiwan's airspace in October 2021 was a demonstrative display of proactive defence. China was not engaged in a direct response to aggression but rather took the initiative in a show of force that was not simply reactive. ${ }^{16}$

Since space, cyberspace and nuclear communities remain largely siloed in China, proactive defence has been relatively slow in crossing between these various domains. However, as China considers countermeasures against and even integration of such US concepts as 'left of launch'-which includes a pre-emptive cyberattack on missile and nuclear infrastructure-there is a greater chance of proactive defence becoming more pronounced not only in terms of concept, but also in terms of practice. ${ }^{17}$

Chinese discussions of pre-emption-as with cyberattacks on command and control in a conventional crisis or conflict-further indicate the dangers of the concept and practice of proactive defence merging with active defence. Entangled or co-mingled platforms and command and control, combined with active shows of force or pre-emptive attacks on critical infrastructure, could trigger nuclear outcomes. ${ }^{18}$ This eventuality, even if remote, demonstrates the importance of better understanding how these concepts are being applied in practice through China's changing postures and technologies.

\section{Postures and technologies enabling proactive defence}

Within multidomain deterrence, China's postural and technological evolution suggests that its traditional markers of active defence are becoming

China is engaged in a potential shift from delayed-launch to launch-onwarning status for its nuclear weapons more proactive in five areas: changes to mating posture, nuclear arsenal size, launch status, dual-capable systems, and machine learning and autonomy. While many of these shifts have been years in the making, President Xi Jinping's own proactive leadership style combined with economic, military and political US pressure on China have contributed to China's accelerated military modernization and compelled its de facto transparency through new tests and deployments.

\section{Mating posture}

China appears to be shifting away from its traditional practice of de-mating, in which nuclear warheads are not mounted on their delivery systems during peacetime. China's sea trials of the Type 096 nuclear-powered

\footnotetext{
15 Based on the author's off-the-record interactions with and presentations by Chinese cyberspace experts in July 2021.

16 'Record number of China planes enter Taiwan air defence zone', BBC News, 5 Oct. 2021.

${ }^{17}$ Greenert, J. W. (Admiral), US Navy, Chief of Operations, and Odierno, R. T. (Gen.), US Army, Chief of Staff, 'Memorandum for Secretary of Defense, Subject: Adjusting the ballistic missile defense strategy', 5 Nov. 2014.

${ }^{18}$ Acton J. M. (ed.) et al., Entanglement: Chinese and Russian Perspectives on Non-nuclear Weapons and Nuclear Risks (Carnegie Endowment for International Peace: Washington, DC, 2017).
} 
ballistic missile submarine (SSBN), flight tests of the JL-3 intercontinental submarine-launched ballistic missile (SLBM) and proliferation of solidfuelled ICBM silos all suggest that, by logistical necessity, China will need to employ pre-mating of its warheads to its delivery systems. ${ }^{19}$ While each of these platforms remains tied to China's second-strike capability, the pre-mating of nuclear warheads to platforms implies a greater potential for accidents or even unsanctioned launches due to issues with communication and delegation-as might occur at sea with an SSBN.

\section{Nuclear arsenal size}

A recent US Department of Defense (DOD) assessment suggested that China may have 700 deliverable nuclear warheads deployed by 2027 and at least 1000 warheads by $2030 .{ }^{20}$ Further, a higher count of nuclear warheads would be required to accompany China's expansion of its stocks of delivery systems, encompassing a growing number of ICBM silos (allegedly to house the MIRVed DF-41 ICBM), and expanded deployment of SLBMs

China's military includes delivery platforms that support both nuclear and conventional military operations and a range of dual-capable unmanned platforms. ${ }^{21}$ Thus, while China's nuclear arsenal remains smaller than Russia's or the USA's, these developments suggest that it is expanding, placing China in a much stronger position to undertake more proactive operations.

\section{Launch status}

China is engaged in a potential shift from delayed-launch to launch-onwarning status for its nuclear weapons. Launch on warning is based on a higher alert status and an ability to launch ICBMs rapidly in the event that early-warning sensors detect an incoming strike. Following a 2014 Chinese publication on building a strategic early-warning system, China is alleged to have deployed communication satellites as early as 2015 to back a launch-onwarning capability. ${ }^{22}$ More recently, China's expansion of the number of its ICBM silos and its favouring of solid-fuelled ballistic missiles suggest that its infrastructure would support a much higher alert level and the ability to engage in more proactive defence.

\section{Dual-capable systems}

China has steadily built up its military to include delivery platforms and command-and-control infrastructure that support both nuclear and conventional military operations. China's dual-capable systems are

\footnotetext{
${ }^{19}$ Korda, M. and Kristensen, H., 'China is building a second nuclear missile silo field', FAS Strategic Security Blog, Federation of American Scientists, 26 July 2021; Torode, G. and Lague, D., 'Special report: China's furtive underwater nukes test the Pentagon', Reuters, 2 May 2019; and Panda, A., 'China conducts first test of new JL-3 submarine-launched ballistic missile', The Diplomat, 20 Dec. 2018.

${ }^{20}$ US Department of Defense (DOD), Office of the Secretary of Defense, Military and Security Developments Involving the People's Republic of China, 2021 (USDOD: Washington, DC, Nov. 2021).

${ }^{21}$ US Department of Defense (note 20).

22 Kulacki, G., China's Military Calls for Putting Its Nuclear Forces on Alert (Union of Concerned Scientists: Cambridge, MA, 2016).
} 
thought to include the DF-17 medium-range ballistic missile (MRBM), the DF-26 intermediate-range ballistic missile (IRBM), the DF-ZF HGV, the $\mathrm{H}-6 \mathrm{~N}$ bomber and the CJ-20 air-launched land-attack cruise missile (LACM), as well as a range of UAVs and UUVs that are under development. ${ }^{23}$ China's recent test of an HGV coupled with a FOBS could be seen as a sizeable step towards not only a dual-capable system, but also a means of greater power projection in both conventional and nuclear contingencies.

\section{Machine learning and autonomy}

China has prioritized the development of systems that are able to learn from data and experience and to operate with limited to no human intervention. ${ }^{24}$

The US response to China's shifts in posture and technologies could trigger an escalatory spiral
As part of this, China has been working on integrating neural networks into HGVs to heighten their manoeuvrability and thus make it easier to penetrate US missile defences. ${ }^{25}$ This is an important development in both conventional and nuclear operations, since these HGVs are already deployed on the DF-17 MRBM, which is not only dual-capable, but also designed for anti-access/area-denial (A2/AD) military operations that are inherently more proactive and potentially even pre-emptive.

China's recent test of an HGV coupled with a FOBS also suggests future longer-range nuclear delivery options, while autonomous systems like UAVs and UUVs may one day carry nuclear payloads, as is reportedly occurring in Russia. ${ }^{26}$ China's new machine learning and autonomy-enabled delivery vehicles could further exacerbate the escalatory issues of discrimination and entanglement, in which conventional and nuclear operations are blurred, thereby opening the potential for China to undertake more proactive regional and global operations.

\section{Conclusions}

Changes to China's postures and technologies indicate that its concept and practice of 'active defence' may be converging with more forward-leaning and even pre-emptive 'proactive defence'. If this is the case, then China may increasingly employ strategies that are more akin to those of the USA and Russia in the space, cyberspace and nuclear domains. The question remains, however, as to whether the increasing similarity of China's postures and technologies with those of Russia and the USA is a destabilizing or stabilizing phenomenon.

One key potentially destabilizing outcome is that the US response to China's shifts in posture and technologies could trigger an escalatory spiral

\footnotetext{
${ }^{23}$ US Department of Defense (note 20); and Boulanin, V. et al., Artificial Intelligence, Strategic Stability and Nuclear Risk (SIPRI: Stockholm, June 2020).

${ }^{24}$ Saalman, L., 'China and India: Two models for AI military acquisition and integration', eds K. P. Bajpai, S. Ho and M. C. Miller, Routledge Handbook of China-India Relations (Routledge: New York, 2020).

${ }^{25}$ Saalman, L., 'China's AI-enabled offense: Hypersonic glide vehicles and neural networks', ed. N. D. Wright, Artificial Intelligence, China, Russia, and the Global Order: Technological, Political, Global and Creative Perspectives (Air University Press: Washington, DC, 2019).

${ }^{26}$ Hruby, J., Russia's New Nuclear Weapon Delivery Systems: An Open-source Technical Review (Nuclear Threat Initiative: Washington, DC, Nov. 2019).
} 
of both arms races and crises that cut across space, cyberspace and nuclear domains. Recent official statements and reports emerging from the US DOD on the 'stunning' pace of Chinese advances, combined with the Russian and US drift away from traditional arms control agreements, suggest that this is a real possibility. ${ }^{27}$

Yet there are also stabilizing outcomes that could develop from China adopting a degree of deterrence with US and Russian characteristics. This growing similarity may afford Russian and US strategists a better understanding of China's postural and technological evolution. China's recent spate of visible tests and deployments have also generated a level of de facto transparency that allows for a better evaluation of its military trajectory. This could make it easier to anticipate its future operations and early crisis management strategies. Most importantly, China's postural and technological shifts place it on a better footing for participation in strategic stability dialogues with the USA, and even eventually in trilateral talks that include Russia. This is because the argument that China's asymmetric weakness precludes its participation erodes as its postures and technologies develop.

China's increasingly proactive stance and capabilities-combined with the very nature of strategic stability dialogues that concentrate more on escalation and crisis management than arms control reductions-suggest a greater impetus for China to engage. Whether bilaterally or trilaterally, strategic stability talks would offer a pathway to moderating China's, Russia's and the USA's employment of weapons during crises, reducing the risk of multidomain escalation turning a conventional conflict into a nuclear one.

\footnotetext{
${ }^{27}$ Burns, R., ‘Pentagon rattled by Chinese military push on multiple fronts’, AP News, 1 Nov. 2021.
} 


\section{Abbreviations}

$\begin{array}{ll}\text { A2/AD } & \text { Anti-access/area-denial } \\ \text { ASAT } & \text { Anti-satellite } \\ \text { DOD } & \text { Department of Defense } \\ \text { FOBS } & \text { Fractional orbital bombardment system } \\ \text { HGV } & \text { Hypersonic glide vehicle } \\ \text { ICBM } & \text { Intercontinental ballistic missile } \\ \text { LACM } & \text { Land-attack cruise missile } \\ \text { MIRV } & \text { Multiple independently targetable re-entry vehicle } \\ \text { MRBM } & \text { Medium-range ballistic missile } \\ \text { NFU } & \text { No first use } \\ \text { SLBM } & \text { Submarine-launched ballistic missile } \\ \text { SSBN } & \text { Nuclear-powered ballistic missile submarine } \\ \text { UAV } & \text { Unmanned aerial vehicle } \\ \text { UUV } & \text { Unmanned underwater vehicle }\end{array}$




\section{RECENT SIPRI PUBLICATIONS ON NUCLEAR ARMS CONTROL}

Reinvigorating South Asian Nuclear Transparency and Confidence-building Measures

Dr Lora Saalman and Dr Petr Topychkanov

SIPRI Insights on Peace and Security no. 2021/4

September 2021

Enhancing South Asian Nuclear Dialogues: The Implications of Covid-19

Dr Petr Topychkanov

SIPRI Policy Brief

September 2021

South Asia's Nuclear Challenges: Interlocking Views from India, Pakistan, China, Russia and the United States

Dr Lora Saalman and Dr Petr Topychkanov

SIPRI Report

April 2021

Artificial Intelligence, Strategic Stability and Nuclear Risk

Dr Vincent Boulanin, Dr Lora Saalman, Dr Petr Topychkanov, Fei Su and Moa Peldán Carlsson

SIPRI Report

June 2020

The Impact of Artificial Intelligence on Strategic Stability and Nuclear Risk, Volume II, East Asian Perspectives

Dr Lora Saalman, Vasily Kashin, Kim Ji-Sun, Vadim Kozyulin, Li Xiang, Arie Koichi, Cai Cuihong, Liu Yangyue, Hwang Il-Soon, Nishida Michiru, Hwang Ji-Hwan, Su Fei and Jiang Tianjiao

SIPRI Report

October 2019

SIPRI publications are available to download at www.sipri.org/publications 
SIPRI is an independent international institute dedicated to research into conflict, armaments, arms control and disarmament. Established in 1966, SIPRI provides data, analysis and recommendations, based on open sources, to policymakers, researchers, media and the interested public.

\section{GOVERNING BOARD}

Ambassador Jan Eliasson, Chair (Sweden)

Ambassador Chan Heng Chee (Singapore)

Jean-Marie Guéhenno (France)

Dr Radha Kumar (India)

Dr Patricia Lewis (Ireland/

United Kingdom)

Dr Jessica Tuchman Mathews

(United States)

Dr Feodor Voitolovsky (Russia)

\section{DIRECTOR}

Dan Smith (United Kingdom)

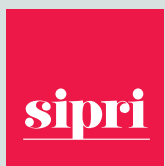

STOCKHOLM INTERNATIONAL PEACE RESEARCH INSTITUTE

Signalistgatan 9

SE-169 72 Solna, Sweden

Telephone: +4686559700

Email:sipri@sipri.org

Internet: www.sipri.org
SIPRI INSIGHTS ON PEACE AND SECURITY NO. 2022/2

\section{MULTIDOMAIN DETERRENCE AND STRATEGIC STABILITY IN CHINA}

LORA SAALMAN

\section{CONTENTS}

I. Introduction 1

II. Multidomain strategic stability 1

III. Active defence and proactive defence 3

IV. Proactive defence in China's multidomain deterrence 4

V. Postures and technologies enabling proactive defence 6

Mating posture 6

$\begin{array}{ll}\text { Nuclear arsenal size } & 7\end{array}$

$\begin{array}{ll}\text { Launch status } & 7\end{array}$

Dual-capable systems $\quad 7$

Machine learning and autonomy $\quad 8$

VI. Conclusions 8

$\begin{array}{ll}\text { Abbreviations } & 10\end{array}$

\section{ABOUT THE AUTHOR}

Dr Lora Saalman (United States) is a Senior Researcher working on SIPRI's Armament and Disarmament and Conflict, Peace and Security research areas. Her research focuses on China's cyber, nuclear and advanced conventional weapon developments in relation to India, Russia and the USA. 